\title{
NOTAS SOBRE COMPETÊNCIAS PROFISSIONAIS NECESSÁRIAS À DOCÊNCIA
}

\author{
NOTES ON PROFESSIONAL SKILLS NECESSARY TO TEACHING
}

\author{
A. Z. $\operatorname{SILVA}^{1}$, e M. L. R SILVA ${ }^{2}$, \\ ${ }^{1}$ Universidade de São Paulo - Doutoranda da Faculdade de Educação FE/USP, Brasil \\ ${ }^{2}$ Universidade de São Paulo - Prof. ${ }^{a}$. Dra . da Faculdade de Educação FE/USP, Brasil
}

\begin{abstract}
ARTICLE INFO
Palavras-chave: Competência Profissional. Identidade

Article history:

Profissional. Formação Docente.

Received 2018-07-02

Accepted 2018-08-17

Available online 2018-08-31

Keywords: Competência Profissional. Identidade Profissional. Formação Docente.

\section{*Autor correspondente:}

E-mail: antoniazs@usp.br

RESUMO. Este texto tem a intenção de discutir alguns aspectos referentes às competências necessárias para o desenvolvimento da profissão docente, em especial, na Educação Básica, conforme as novas exigências culturais, sociais e políticas. Como procedimento metodológico deste artigo, concentrou-se na compreensão de leituras e interpretações de textos sobre as competências fundamentais para a profissão docente. Foram tomados como aportes teóricos os seguintes pesquisadores: Gatti (2013); Nóvoa (1999); Perrenoud, (2002); Machado (2009) e Rios (2005). Após as leituras, pode-se inferir que a profissão docente implica entender a aprendizagem como um processo contínuo, alicerçada na busca da compreensão de novas competências e valores para uma educação que atenda aos anseios de uma sociedade contemporânea, para se alcançar uma educação de qualidade. Essa ressignificação só será possível por meio de mudanças significativas na formação e na identidade profissional daqueles que se dedicam à profissão de professor.
\end{abstract}

ABSTRACT. This text aims to discuss some aspects related to the necessary competences for the development of the teaching profession, especially in Basic Education, according to new cultural, social and political requirements. As a methodological procedure of this article, it focused on the comprehension of readings and interpretations of texts about the fundamental competences for the teaching profession. The following researchers were taken as theoretical contributions: Gatti (2013); Nóvoa (1999); Perrenoud, (2002); Machado (2009) and Rios (2005). After the readings, it can be inferred that the teaching profession implies understanding learning as a continuous process based on the search of understanding new competences and values for an education that meets the aspirations of a contemporary society in order to reach quality education. This re-signification will only be possible by means of significant changes in professional education and identity of the ones engaged in the teaching profession.

\section{Considerações Iniciais}


Todos nós, professores, já ouvimos o quanto é essencial uma adequada formação inicial e continuada ao longo da nossa trajetória profissional, para atender às novas exigências culturais, sociais e políticas. Para tanto, faz-se necessário um profissional que reflita sobre a sua prática e as ações educativas. Esse movimento envolve novos processos de formação, para estabelecer novas competências e saberes exigidos para esse novo profissional da educação do século XXI.

$O$ presente artigo tem a intenção de discutir alguns aspectos referentes às competências necessárias para se desenvolver a profissão docente, em especial, na Educação Básica, visto que a formação de professores vem sendo amplamente discutida no cenário das práticas pedagógicas, tanto em âmbito nacional quanto internacional.

Para uma educação de qualidade, é necessária uma formação que não se restrinja a uma aprendizagem meramente acadêmica, isto é, sem descuidar da formação plena do ser humano, de forma a considerar as temáticas atuais ao contexto contemporâneo, para que possa haver mudanças significativas na formação e na identidade profissional daqueles que ingressam na carreira de professor.

O estudo das temáticas formação docente e competências valida-se pela necessidade de se compreender como a problemática da formação docente foi posta e como a mesma pode servir para um debate que aponte para um melhor impulsionar na educação face à qualidade do ensino ofertado, em especial, na Educação Básica.

Para atuar como professor, a Lei de Diretrizes e Bases da Educação - LDB, Lei no 9.394/96, define que "a formação de docentes para atuar na educação básica far-se-á em nível superior, em curso de licenciatura, de graduação plena, em universidades e institutos superiores de educação" (BRASIL, 1996).

A formação docente, à luz dos principais elementos para melhoria da educação:

[...] faz-se necessária uma revisão profunda dos diferentes aspectos que interferem na formação inicial de professores, tais como: a organização institucional, a definição e estruturação dos conteúdos para que respondam às necessidades da atuação do professor, os processos formativos que envolvem aprendizagem e desenvolvimento das competências do professor, a vinculação entre as escolas de formação inicial e os sistemas de ensino. (BRASIL, 2000, p. 12 - grifo nosso)

Como citado acima, são muitas as variáveis que interferem ou formam um profissional apto para exercer a função de docente e com as competências necessárias para atuar como professor na Educação Básica.

Para Nóvoa (1995), a função de professor exige: 
[...] além de saber a matéria que leciona, pede-se ao professor que seja facilitador da aprendizagem, pedagogo eficaz, organizador do trabalho em grupo, e que, para além do ensino, cuide do equilíbrio psicológico e afectivo dos alunos, da integração social e da educação sexual, etc.; a tudo isto pode somar-se a atenção dos alunos especiais integrados na turma. (NÓVOA, 1995, p. 100)

Como se pode ver, atualmente, as exigências são muito mais do que conhecimento específico para desenvolver o trabalho de professor; assim, a importância de os cursos de licenciatura acompanharem essas mudanças, para possibilitar aos professores atenderem a todas essas novas competências e saberes educacionais do século XXI.

Para Gatti (2009), a formação dos professores requer uma reorganização para atender às:

[...] exigências mais claras quanto às suas competências e habilidades na direção de serem detentores de saberes teórico-práticos que lhes permitam desenvolver, criar, ampliar os aspectos formativos específicos relativos ao desenvolvimento da educação escolar em suas variadas facetas. (GATTI, 2009, p. 95)

Para fundamentarmos este estudo, tomamos como referenciais teóricos os autores que discutem a formação de professores com as proposições para o século XXI, como Gatti (2013); Nóvoa (1999); Perrenoud, (2002); Machado (2009) e Rios (2005).

O artigo está estruturado da seguinte forma: partindo das considerações iniciais, na sequência, apresentamos os caminhos da construção deste estudo; após, expomos algumas exigências para ser professor no século XXI; passamos pelas competências à docência de uma sociedade contemporânea, chegando às competências necessárias à docência nas concepções de alguns pesquisadores; por fim, apresentamos as considerações finais e as referências.

\section{Caminhos Percorridos}

Este artigo é de natureza qualitativa, realizado por meio de análise documental, cujo foco se concentra na compreensão de leituras e interpretações a respeito das competências fundamentais para a profissão docente.

A pesquisa qualitativa assume distintos significados no campo das ciências sociais. Segundo Maanen (1979), a pesquisa qualitativa compreende um conjunto de diferentes técnicas interpretativas que visam descrever e decodificar os componentes de um sistema complexo de significados.

Desse modo, o seu desenvolvimento foi por meio do levantamento e estudo de artigos, livros e revistas que versam sobre as competências essenciais para os professores no século XXI, como, por exemplo, Perrenoud, (2002); Machado (2009) e Rios (2005). 


\section{Ser Professor no Século XXI}

A concepção de competência é muito importante na orientação da formação inicial e continuada de professores, pois as:

[...] competências tratam sempre de alguma forma de atuação, só existem "em situação" e, portanto, não podem ser aprendidas apenas pela comunicação de ideias. Para construí-las, as ações mentais não são suficientes - ainda que sejam essenciais. Não basta a um profissional ter conhecimentos sobre seu trabalho; é fundamental que saiba fazê-lo. (BRASIL, 2000, p. 35)

Como citado acima, os nossos conhecimentos teóricos são postos à prova quando temos que mobilizá-los em prol de uma situação, de tal forma que se relacione a teoria com a prática, melhor dizer, quando é aplicado o conhecimento teórico em uma ação prática dentro ou fora do contexto escolar.

A temática competência profissional para exercer a docência é constantemente debatida em âmbito nacional e internacional, tendo em vista a (re) construção da identidade de professor, que passa pela necessidade de assumir a dimensão profissional de seu trabalho, contrapondo-a à visão de sacerdócio.

Conforme Silva (2009, p. 8), "as habilidades para o exercício do trabalho modificamse vertiginosamente"; em cada época usamos um conceito para definir um bom profissional, visto que:

[...] o conceito de competência, antes de mais nada, significa, o fato de estar preparado para desempenhar várias atividades, de ter predisposição atitudinal para enfrentar problemas, [...] e de ter a capacidade para aprender a todo instante os conteúdos relacionados àquelas atividades que exerce em seu cotidiano. (SILVA, 2009, p. 8)

Assim, um profissional competente está sempre aprendendo, ou melhor, ele precisa, após a formação inicial, investir em sua formação permanentemente, pois, com as novas demandas da sociedade, a formação tornou-se um processo contínuo de novos conhecimentos e metodologias para não ficar com uma prática absoleta em sala de aula, sem prestigiar a integração da totalidade do ser humano, o agir e pensar dos sujeitos envolvidos no contexto escolar e extraescolar.

Para Perrenoud (2002), é imprescindível que os professores despendam de:

[...] energia e tempo e dispor das competências profissionais necessárias para imaginar e criar outros tipos de situações de aprendizagem, que as didáticas contemporâneas encaram como situações amplas, abertas, carregadas de sentido e de regulação, as quais requerem um método de pesquisa, de identificação e de resolução de problemas. (PERRENOUD, 2002, p. 25) 
Para alcançarem essas competências, os professores devem ter claramente o domínio dos conhecimentos específicos da sua área de atuação e também a compreensão das questões que envolvem a dimensão do ambiente de trabalho, para que possam ter autonomia para tomar decisões no contexto interno e externo à sala de aula, com responsabilidade pelas suas escolhas enquanto profissionais.

Atualmente, as demandas escolares exigem que os professores saibam avaliar criticamente a sua própria atuação no contexto em que atuam, e que saibam, ainda, interagir coletivamente com os seus pares, para fomentar a contínua construção do conhecimento dos seus alunos.

A formação inicial deve propiciar o desenvolvimento de competências essenciais para dar condições de trabalho aos profissionais da educação, tanto pela sua formação básica na graduação, como pela experiência com a prática docente no estágio, durante a licenciatura nas instituições de ensino.

Para Gatti (2013), é necessário:

[...] ressaltar que esse desenvolvimento profissional parece, nos tempos atuais, configurar-se com condições que vão além das competências operativas e técnicas associadas ao seu trabalho no ensino, tornando-se uma integração de modos de agir e pensar, implicando um saber que inclui a mobilização não só de conhecimentos e métodos de trabalho, como também de intenções, valores individuais e grupais, da cultura da escola; inclui confrontar ideias, crenças, práticas, rotinas, objetivos e papéis, no contexto do agir cotidiano, com as crianças e jovens, com os colegas, com os gestores, na busca de melhor formar os alunos, e a si mesmos. (GATTI, 2013, p. 35)

A partir do exposto por Gatti (2013), é indispensável que na formação inicial dos professores, discuta-se e favoreça o desenvolvimento de competências para uma educação básica de qualidade, visto o tamanho do desafio de ser professor. E essas não podem se restringir somente às competências técnicas, mas também abranger todas as suas dimensões, como, por exemplo, ética, estética, política e técnica, durante todo o curso de licenciatura.

Atualmente, a sociedade está passando por um movimento de ressignificações de valores e saberes. Para Silva (2007, p. 257), "podemos afirmar que os saberes ligados ao trabalho são temporais, pois são construídos e dominados progressivamente durante um período de aprendizagem."

Uma vez que passamos por mudanças culturais, sociais e políticas, logo, emergem as exigências por profissionais com um arcabouço de conhecimentos, competências, aptidões e atitudes específicas que só podem ser adquiridas e dominadas com a formação contínua.

Para o educador e pesquisador Nóvoa, a formação se dá em: 
[...] um ciclo que abrange a experiência do docente como aluno (educação de base), como aluno-mestre (graduação), como estagiário (práticas de supervisão), como iniciante (nos primeiros anos da profissão) e como titular (formação continuada). Esses momentos só serão formadores se forem objeto de um esforço de reflexão permanente. (NÓVOA apud GENTILE, 2001, p.14)

Assim, o crescimento profissional se dá ao longo do tempo, com a experiência do trabalho e nos momentos de reflexão sobre a própria ação, conhecimentos e competências desenvolvidas no contexto escolar frente às novas exigências.

A seguir, apresentaremos algumas competências necessárias para atender às exigências da docência em tempos de constantes transformações em que nos encontramos.

\section{As Competências no Contexto Educacional}

Há uma tendência observada nas últimas décadas, nas pesquisas realizadas, sobre a discussão da necessidade de um equilíbrio no processo de ensinar e aprender, em âmbito nacional e internacional, que alerta as instituições para essa necessidade. Esse equilíbrio se faz necessário na formação inicial e continuada dos professores, consequentemente, as instituições de formação devem rever os saberes e as competências necessárias dos profissionais que vão atuar na Educação Básica como docentes, independente da disciplina ou área de conhecimento.

Olhando para a atuação do professor, a aprendizagem é um processo que se divide em ensinar e aprender, que deve se concretizar de forma progressiva através de espaços e tempos de interação no contexto escolar; logo, é essencial uma intervenção fundamentada e contextualizada por parte dos professores em suas aulas, sendo capazes de criar condições para que cada estudante possa progressivamente ser autônomo e também desenvolver as suas capacidades de aprender a aprender.

As Diretrizes Curriculares alertam para as mudanças no cenário da educação, e clamam por um novo profissional que saiba conviver com uma grande heterogeneidade de alunos, pois:

O contexto atual traz a necessidade de promover a educação escolar, não como uma justaposição de etapas fragmentadas, o que tem acontecido até aqui, mas numa perspectiva de continuidade entre educação infantil, ensino fundamental e ensino médio, dando concretude ao que a legislação denomina educação básica e que possibilite um conjunto de aprendizagens e desenvolvimento de capacidades que todo cidadão - criança, jovem ou adulto - tem direito de desenvolver ao longo da vida, com a mediação e ajuda da escola. (BRASIL, 2000, p.8) 
É amplamente reconhecido que somente profissionais bem formados e comprometidos com o ensino e a aprendizagem dos alunos para dar sustentação a uma educação básica de qualidade possibilitam que os alunos desenvolvam as competências de aprender a aprender ao longo da vida.

Segundo Perrenoud (2000), para esse professor é necessária uma formação que passe:

[...] pelo conjunto do currículo e por uma prática - reflexiva - dos valores a incutir. E, ainda aqui, as intenções de formação confundem-se com as exigências da vida cotidiana. Lutar contra os preconceitos e as discriminações sexuais, étnicas e sociais na escola não é só preparar o futuro, mas é tornar o presente tolerável e, se possível, fecundo. Nenhuma vítima de preconceitos e de discriminações pode aprender com serenidade. (PERRENOUD, 2000, p. 147)

Como toda profissão, a docência tem sua trajetória construída historicamente, passando por interferências dos contextos culturais, políticos e sociais. Dessa forma, não há espaço para o sacerdotismo pela docência; então, faz-se necessário que se discutam as competências e habilidades para a real profissão da docência do século XXI.

As Diretrizes Curriculares para a formação inicial de professores para a Educação Básica ressaltam que ser professor requer formação inicial e continuada, e estas devem promover a flexibilidade, produtividade e eficiência no seu fazer pedagógico, não podendo ser confundido com um sacerdote, como colocado abaixo:

[...] o professor, como qualquer outro profissional, lida com situações que não se repetem nem podem ser cristalizadas no tempo. Portanto, precisa permanentemente fazer ajustes entre o que planeja ou prevê e aquilo que acontece na interação com os alunos. Boa parte dos ajustes tem que ser feitos em tempo real ou em intervalos relativamente curtos, minutos e horas na maioria dos casos - dias ou semanas, na hipótese mais otimista - sob o risco de passar a oportunidade de intervenção no processo de ensino-aprendizagem. Além disso, os resultados do ensino são previsíveis apenas em parte. O contexto no qual se efetuam é complexo e indeterminado, dificultando uma antecipação dos resultados do trabalho pedagógico. (Brasil, 2002, p. 35)

Diante do exposto, fica evidente que o professor deve ser um profissional comprometido com a sua própria formação, e não aquele "que se qualifica unicamente por seus dotes pessoais de sensibilidade, paciência e gosto no trato com crianças, adolescente e jovem e adulto" (Brasil, 2000, p. 29).

Dessa maneira, a formação inicial tem um papel crucial que pode possibilitar que os professores se apropriem de determinados conhecimentos e (re) conheçam, em seu próprio processo de aprendizagem, o desenvolvimento de competências necessárias para atuarem em um novo contexto escolar, com as novas exigências postas pela sociedade e pelas políticas públicas. 
Diante do exposto até aqui, quais os atributos esperados para a profissão docente, isto é, quais são as competências necessárias para uma docência de qualidade, neste século, para atuar na Educação Básica?

Atualmente, a relação entre ensino e aprendizagem está passando por uma descontinuidade com o paradigma da transmissão do conhecimento e ascensão do modelo emergente do mundo contemporâneo.

Para Nóvoa (2001, p.11), a "educação vive um tempo de grandes incertezas e de muitas perplexidades. Sentimos a necessidade da mudança, mas nem sempre conseguimos definir the o rumo. Há um excesso de discursos, redundantes e repetitivos, que se traduz numa pobreza de práticas".

Logo, o desafio atual da docência no mundo contemporâneo é rever a formação inicial e continuada e como o professor tem desenvolvido o seu trabalho no espaço da sala de aula, reorganizando os seus saberes e competências em prol da qualidade da docência e da realização pessoal; consequentemente, quais competências são exigidas para esse novo profissional da educação?

Para que as pessoas que exercem a docência tenham um reconhecimento profissional pela sociedade, é indispensável que estas apresentem "um domínio adequado da ciência, técnica e arte da mesma", ou seja, que evidenciem que possuem competência profissional (NORBERGUE, 2016, p. 190).

Dessa forma, há uma relação implícita entre docência e competência, ou melhor, o docente precisa ser competente em sua profissão para que haja qualidade em seu trabalho, assim como em qualquer outra profissão. Para isso, a formação desse profissional precisa ser adequada à época, isto é, ao "modelo de sociedade e do ser humano que queremos" (Perrenoud, 2002, p.12).

Dessa maneira, para cada época as exigências das competências profissionais se traduzem de maneira diferente no trabalho. Hoje em dia, discute-se e estuda-se como desenvolver as competências enquanto docente em todas as suas dimensões, técnica, estética, política e ética, para a autonomia do ser humano enquanto sujeito responsável pelo seu próprio desenvolvimento.

Para Rios (2005), falar em competência significa falar em saber fazer bem; também alerta que a competência não tem apenas um único sentido, como vem sendo usado indiscriminadamente o termo, sendo confundido simplesmente com o ato de realizar uma tarefa puramente mecânica (tecnicista).

Para os pesquisadores Perrenoud (2002), Rios (2005) e Machado (2009), as competências são extremamente importantes no processo de formação tanto do educador quanto do aluno, uma vez que há várias dimensões para as competências nos âmbitos 
pessoal e profissional, que são importantes e necessárias para uma docência de qualidade, assim como para o exercício da profissão docente em tempos atuais no ambiente escolar.

Na perspectiva de Perrenoud (2002), a formação dos professores precisa ser revista para atender uma nova geração de alunos (público heterogêneo); também muitos alunos de licenciatura (futuros professores) acreditam que apenas dominar os conteúdos seja suficiente para atuarem como docentes, não desenvolvendo nem discutindo as demais dimensões de competências.

Para o autor, os cursos de formação não preparam os futuros professores para uma lista de situações além dos saberes técnicos, por exemplo, "medo, sedução, o poder, o conflito, a improvisação, a solidão, o tédio, a rotina", sendo que os professores precisam de competências que indiquem os saberes e as capacidades necessárias para lidarem com essas situações acima citadas (PERRENOUD, 2002, p.18).

Do ponto de vista de Rios (2005), a qualidade da docência passa pelos campos dos saberes e das competências, por isso, a importância da compreensão das dimensões de uma competência pelos profissionais da educação.

Uma breve descrição das dimensões de uma competência: técnica - certa forma de fazer; estética - sensibilidade, "docência e boniteza de mãos dadas"; ética - caráter, respeito, solidariedade e bem coletivo; política - construção coletiva da sociedade, articulada pelas dimensões técnica, estética, e todas essas são mediadas pela ética (RIOS, 2005).

No final da década de noventa, a UNESCO apresentou os quatros pilares para uma educação de qualidade, sob a coordenação de Jacques Delors, em que se propõe um direcionamento para a formação integral do ser humano a partir dos seguintes princípios: aprender a conhecer, aprender a fazer, aprender a conviver e, por último, aprender a ser, possibilitando, assim, que se construa significado para aqueles que aprendem ao longo da vida.

O professor deve ter como parâmetro a sua formação e a formação de seus alunos, e esses princípios são denominados pilares da educação, de forma que, quando compreendidos e aplicados na educação, podem favorecer o desenvolvimento integral do ser humano, alcançando seu pleno desenvolvimento, ou seja, alcançando sua totalidade enquanto sujeito, sendo capaz de aprender a conhecer, a fazer, a conviver e a ser.

\section{Competências fundamentais para a docência}

Perrenoud (2002), em seu livro, 10 novas competências para ensinar, apresenta uma lista de competências necessárias aos professores, são elas: 
1. Organizar e dirigir situações de aprendizagem; 2. Administrar a progressão das aprendizagens; 3 . Conceber e fazer evoluir os dispositivos de diferenciação; 4. Envolver os alunos em sua aprendizagem e em seu trabalho; 5. Trabalhar em equipe; 6. Participar da administração da escola; 7. Informar e envolver os pais; 8. Utilizar novas tecnologias; 9. Enfrentar os deveres e os dilemas éticos da profissão; 10. Administrar sua própria formação contínua. (PERRENOUD, 2002, p. 14).

Para o autor, essas competências são imprescindíveis para um professor poder trabalhar, ou seja, ensinar em uma sociedade em que o conhecimento está cada vez mais acessível a todos e em qualquer lugar.

Na concepção de Machado (2009), as competências fundamentais para uma atuação da docência em sala de aula perpassam por um conjunto de ações e funções realizadas pelo professor, como, por exemplo, tecelão, cartógrafo, contador de histórias, mediador e tolerante, como exposto abaixo.

[...] um professor competente é como um tecelão, tecendo pacientemente relações entre os temas mais diversos, na construção dos significados; é cartógrafo, mapeando relevância, tendo em vista os projetos de seus alunos; é um contador de histórias, de narrativas fabulosas, que despertam o encantamento e alimentam desejos; é um mediador de conflitos, de todos os tipos, sobretudo o de interesses ao fato de iniciar algo nos outros; e é, necessariamente, um semeador da tolerância, do respeito pela diversidade. (MACHADO, 2009, p. 61- grifo nosso)

De acordo com Machado (2009), pode-se dizer que os verbos mediar, tecer, mapear e construir dão o direcionamento de um profissional competente.

Pode-se entender que mediar conflitos de interesses entre professor e aluno se dá por meio da sensibilização e argumentação; ao tecer redes de significados, o professor é um construtor de encadeamento de temas aparentemente desconectados; ao mapear valores e/ou projetos, o professor é um cartógrafo que constrói mapas de relevância e significação; e ao construir narrativas fabulosas, o professor é um contador de histórias, qualquer tema pode ser explicado por meio de uma narrativa/história.

Considerando-se as competências profissionais para uma docência de qualidade como as citadas pelos pesquisadores/educadores acima, pode-se inferir que todos assinalam a necessidade de profissionais competentes, não somente na dimensão técnica, mas em todas as destacadas, para possibilitar um ensino de qualidade para todos os alunos.

Para se conseguir uma educação de qualidade, é essencial uma mudança significativa na formação e na identidade dos profissionais que se dedicam à profissão de professor, sem deixar de lado o desenvolvimento das novas competências exigidas no século XXI. 
Para Nóvoa (1995, p.11), "a educação vive um tempo de grandes incertezas e de muitas perplexidades"; também ressalta a necessidade da mudança, mas nem sempre é fácil definir quais mudanças e seu rumo. Mas uma coisa é certa: "há um excesso de discursos, redundantes e repetitivos, que se traduz numa pobreza de práticas".

A formação inicial e a continuada devem favorecer a instrumentalização dos professores, para desfazerem o paradoxo entre teoria e prática e, assim, aproximarem o discurso da prática em sala de aula.

Essa formação deve ser vista como um processo permanente integrado à rotina dos docentes, propiciando, de forma mais ampla, competências que tornem os indivíduos capazes de enfrentar inúmeras situações, as quais, às vezes, são aleatórias, além de facilitar o trabalho em equipe, que, atualmente, é uma dimensão negligenciada pelos métodos de ensino nas instituições.

Também não citado explicitamente até o momento, mas não menos importante, é o atual contexto escolar, visto que existem outros atores além dos professores e alunos, outras variáveis envolvidas no processo de ensino e aprendizagem, que tornam o ambiente escolar muito dinâmico, complexo e não estático, onde todos esses fatores influenciam nos resultados almejados pelos profissionais da educação, assim como o desenvolvimento das competências fundamentais para uma docência de qualidade.

\section{Considerações Finais}

Como foi apresentado ao longo deste artigo, há a necessidade de uma formação inicial e continuada que valorize a construção da noção de competência com todas as suas dimensões, com a perspectiva de uma formação dinâmica, flexível, condizente com a ênfase atual no trabalho em equipe, proporcionando o pleno desenvolvimento das competências para a profissão docente, possibilitando mudanças que provêm da "desmaterialização" do trabalho que exige, além da técnica, a "aptidão para as relações interpessoais" (Delors, 2003, p. 95).

A profissão docente implica entender a aprendizagem como um processo contínuo, e requer novas dimensões de conceitos alicerçados na busca da compreensão de novas competências e valores para uma educação que atenda aos anseios de uma sociedade contemporânea.

Consequentemente, é preciso buscar não só o desenvolvimento de competências, mas, essencialmente, uma mudança significativa na formação e na identidade profissional dos que se dedicam à profissão de professor para se conseguir uma educação de qualidade. 
Quanto ao desenvolvimento de competências, fica evidente que o docente necessita estar em constante formação, e esta deve levá-lo a desejar prosseguir aprendendo para poder desempenhar com qualidade sua profissão, uma vez que as competências são construídas por toda a vida e mobilizam conhecimentos.

\section{Referências}

BRASIL. Proposta de Diretrizes para a Formação Inicial de Professores da Educação Básica. Brasília/DF, 2000.

Lei n. 9.394 de 20 de dezembro de 1996 - Estabelece as Diretrizes e Bases da Educação Nacional. Brasília/DF, 1996.

DELORS, J. Educação um tesouro a descobrir. Relatório para a Unesco da Comissão Internacional sobre a Educação para o Século XXI. 6. ed. Tradução José Carlos Eufrázio. São Paulo: Cortez, 2001.

GATTI, B. A. A formação inicial de professores para educação básica: as licenciaturas. Revista USP. São Paulo, n. 100, p. 33-46. Dezembro/Janeiro/Fevereiro 2013-2014.

GENTILE, P. Fala Mestre! Philippe Perrenoud - A arte de construir competências. Nova Escola. São Paulo, n. 135, p. 14-20, set. 2000.

Fala Mestre! Antônio Nóvoa - Professor se forma na escola. Nova Escola. São Paulo, n. 142, p. 13-15, mai. 2001.

MAANEN, J. V. Reclaiming qualitative methods for organizational research: a preface, In: Administrative Science Quarterly, vol. 24, no. 4, December 1979.

MACHADO, N. J. Competência dos professores. In__Educação: autoridade, competência e qualidade. São Paulo, Escrituras Editoras. 2009.

NÖRNBERG, N.E.; FORSTER, M. Ensino Superior: as competências docentes para ensinar no mundo contemporâneo. Revista Docência do Ensino Superior, v. 6, n. 1, p. 187210, abr. 2016.

NÓVOA, A. Formação de professores e preparação docente. In: (Coord.). Os Professores e sua formação. Lisboa: Publicações Dom Quixote, 1995. p. 13 - 33.

PERRENOUD, P. et al. As competências para ensinar no século XXI: a formação dos professores e o desafio da avaliação. Porto Alegre: Artmed, 2002.

RIOS, T. A. Compreender e Ensinar: por uma docência de melhor qualidade. 5a . ed. São Paulo: Cortez, 2005. 
SILVA. M. L. R. Aspectos sócio-afetivos que interferem na construção da identidade do professor. In: SILVA, Elisabeth Ramos da; UYENO, Elzira Yoco; ABUD, M José Milharezi. Cognição, Afetividade e Linguagem. Taubaté. Cabral Editora e Livraria Universitária, 2007 (p. 235-260).

A Complexidade inerente aos Processos Identitários Docentes.In: Revista Not andum Libro, v. 12, p. 45-58, 2009. 